\title{
4.4 The principles and elements of enterprise investment policy-making
}

Investment planning is a complex process, one of the elements of long-term enterprise planning. It can be divided into several time periods and cover all activities of the enterprise.

Long-term planning covers many areas of the enterprise: corporate strategy, financing, production technology, research, training, marketing, customer relations, etc. Investments are needed in most of these areas. They are the least mobile element of planning, because investments are not only planned for a long time, but it is important to choose the optimal time. Long-term planning reflects the thinking and leadership style of the company associated with its strategic plans.

As practice shows, the development of long-term investment planning has big potential. The strategic planning focused on the formation of long-term plans contributes to a more efficient allocation of investment resources in accordance with the development strategy of the enterprise. Specific results obtained by scientists based on the analysis of a large amount of information about mergers and acquisitions of American firms indicate the following $[268,271]$. Conscious, systematic preliminary development of the strategy provides much higher financial performance of the enterprise than the lack of a plan and action depending on the specific situation. The reliability of the obtained results is confirmed by their strict statistical verification. In addition, a number of other studies have confirmed that an open strategy improves business performance.

In conditions of fierce competition, long-term investment planning gives to management substantial competitive advantages.

Long-term planning is both a cause and a consequence of enterprise development. Long-term planning makes it possible to make better use of the time factor, to shorten the path to the intended goal. In industrial practice, events are usually unpredictable. There are sharp changes in market conditions, there are fundamentally new technologies, there are significant changes in management. Nevertheless, long-term planning allows to maintain the correct general orientation in the market space. The 
competitiveness of products and the level of enterprise development depend on the speed and flexibility of maintaining this orientation, activity and realism of the implementation of long-term planning through short-term decision-making.

The investment planning is an important part of long-term enterprise planning. Therefore, the purpose of the enterprise plays an important role in investment planning. The actual formulation of the investment goals in accordance with the defined purpose of the enterprise, the basic principles and methods mean that the company has and implements its investment policy. Investment process management includes investment planning based on the analysis of possible planning options (ideas) and analysis of their effectiveness (profitability), as well as investment control.

When planning investments, an analytical assessment of the costs they require is carried out; the profitability must be assured and the distribution of investments over time. The time characteristics of the investments distribution are of particular importance, as effective management of investment processes of the enterprise can be carried out only when forecasting investments for at least five to ten years. The task of investment planning is to ensure the continuity and rhythm of the whole set of works on the reproduction of fixed assets (FA), as well as high economic efficiency of investments. An important task of investment planning and capital development is to balance them with material, labor and financial resources, equipment and capacity of construction needed for installation of organizations and departments. The practice of managing investment processes on enterprises includes short-term and long-term investment planning. The latter is characterized by a division into several time periods to cover all the activities of the enterprise.

Investment policy includes defining the purpose of investment in accordance with the basic principles and methods of their planning and control.

Decision-making about investments involve, above all, the coordination of individual long-term plans over time, bringing them to a single coordinated plan. For example, when planning the replacement of depreciated equipment with new ones, in addition to consistent coordination of plans over time, the possibility of their parallel coordination should be taken into account. This is especially important in conditions 
where different types of investments complement each other, or when it is profitable to invest in several different objects at the same time. In each case a combination of investments that best meets the production goal (strategic goals) of the enterprise should be performed.

When planning investments, it is important to coordinate not only plans but also production functions (manufacture, sale, purchase, administration, financing, etc.). After all, in order to make a profit, the company needs to perform not only the production and technical direction of investments, but also the organization of sales for products manufacturing.

As the analysis of investment management practices show, the investment policymaking should be based on all the above principles, which ensures their complexity and efficiency. This primarily applies to enterprises that are actively developing and expanding. At the same time, the faster the company develops, the more difficult it is to manage investment processes, coordinate various investment plans.

The length of Investments time periods leads to the fact that when planning in addition to the balance of investment their reliability should be taken into account. Investment planning is carried out for the future, so it always has a degree of uncertainty. This should be taken into account at the stage of making plans. In fact, determining the reliability of investments requires the need for constant review of the plans, which is associated with a constant long-term planning. Therefore, the management of the enterprise in the conditions of changing landscape of its operations should provide periodic review of investment plans and adapt them to new conditions.

Therefore, the main principles of investment planning and control are the following:

- determining the purpose of investment;

- coordination of individual investment plans (their elements) over time; -coordination of production functions (purchase of necessary raw materials, components, equipment; production and sale; administrative activities; financing, etc.);

- taking into account the uncertainty (reliability) of investments;

- periodic review of investment plans; 
- organization of constant control of investments.

Investment planning and control is a complex process in which the following most important components can be identified:

- research and study of the investment object;

- determination of quantitative characteristics of different investment options;

- comparative analysis of options and investment calculations;

- financing of investments, development of the project plan taking into account features of object of investments and financing possibilities;

- decision-making on investment and development of a plan for its implementation;

- control of investments during their implementation and in their subsequent stages.

Investment planning and control is a complex process in which the following most important components can be identified:

- research and study of the investment object;

- determination of quantitative characteristics of different investment options;

- comparative analysis of options and investment calculations;

- financing of investments, development of the project of the plan taking into account features of object of investments and possibilities of financing;

- decision-making on investments and development of a plan for its implementation;

- control of investments during their implementation and in their subsequent stages.

Investment ideas appear as a result of a systematic search for the object of investment, for which large enterprises have special research units; other companies use particular funds for this purpose. The organization of use of the specified means does not demand special training of the personnel; more important is the right attitude of management to the search for investment options, which is to encourage more staff to seek ideas and apply various incentives. 
The study of foreign economic practice shows that effective organizational forms in the development of investments are planning committees (groups), whose task is to guide the work on planning or direct implementation of these works. By the nature of their activities, they can be two different types of bodies involved:

- implementation of ideas, ie guide and control the search for ideas, evaluate and develop them;

- search for ideas, ie generate ideas that are further developed and evaluated.

The implementation of investment ideas can also be entrusted to one employee, who has a number of employees.

The production experience has shown a rational decentralization of the search for ideas and centralization of their implementation. It is important to create a certain organizational mechanism at different levels for the promotion, development and evaluation of investment ideas. Investment plans for significant reconstruction of the enterprise or for investment in a completely new field of activity require flexible development and coordination at various organizational levels.

When developing investment policy, it is important to identify development trends. Promising development of individual factors stems from the main trends in enterprise development, which are by extrapolation of existing trends.

When identifying trends in the investment planning process, the following groups should be considered:

- general economic trends;

- industry trends;

- trends that operate within a particular enterprise.

When identifying industry trends, it is important to analyse in which direction the industry is developing in relation to overall economic growth and what are the opportunities for development, taking into account general economic factors.

When identifying trends in the development of a particular enterprise, they should be evaluated based on general economic trends and industry trends. The scheme of the mechanism of their investment policy formation on the basis of the tendency development analysis is shown on fig.1. 


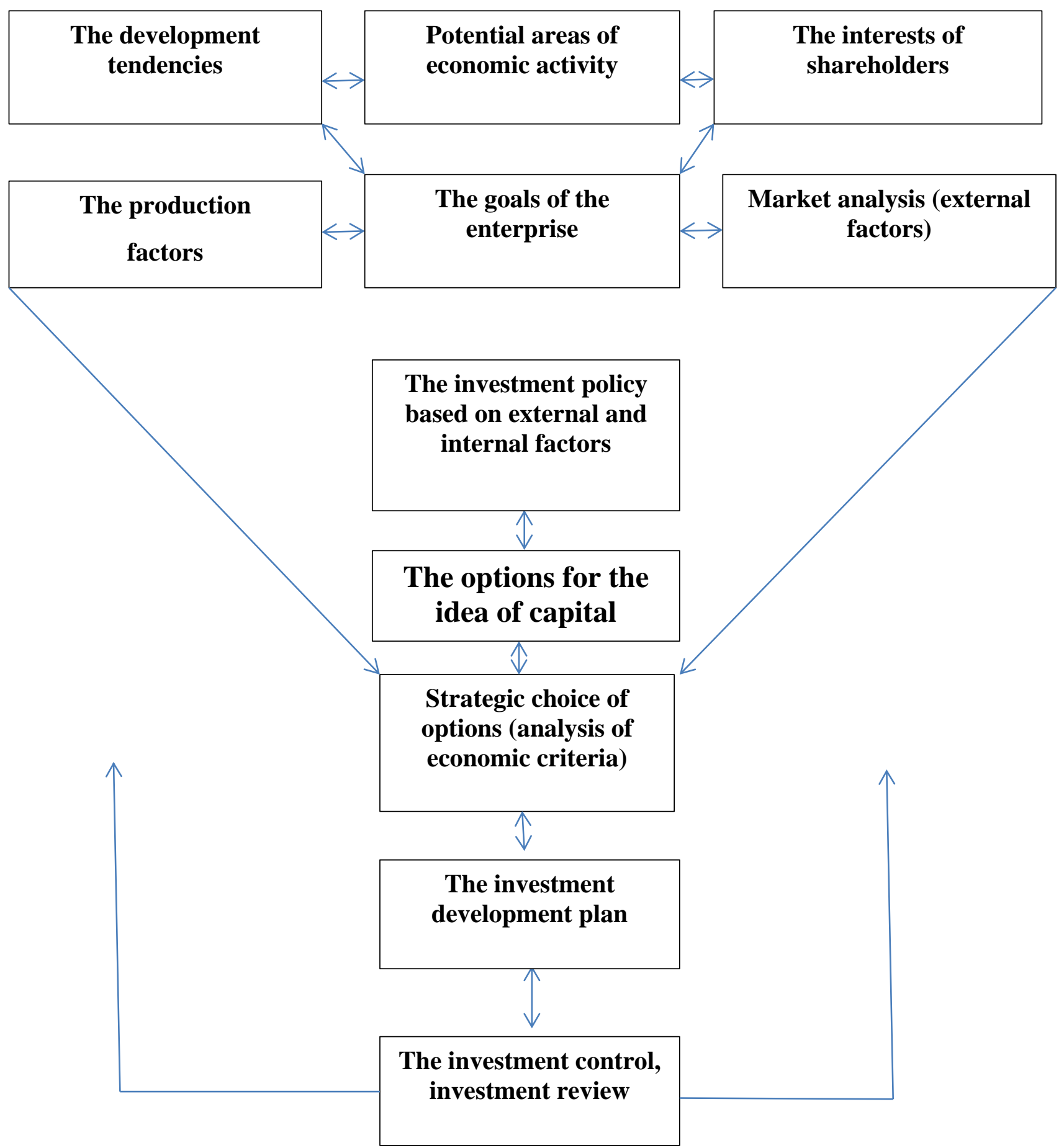

Fig.1. The mechanism of investment's policy formation

In the practice of European and American enterprises it is accepted to group investments by the following classes depending on their purpose [272]:

1) Obligatory investments;

2) Investments oriented on maintaining market positions;

3) Renewal of fixed assets (especially the active part of FA); 
4) Cost savings;

5) Increase in income;

6) "risky" investments.

The first group includes investments that are made to improve the reliability and safety of production, environmental purposes or other mandatory circumstances.

The second group covers the investments required to maintain the company's market position, maintain its position and build a reputation.

Investments of the third group are designed to maintain the stable operation of the enterprise and increase the technical level of production.

The fourth group includes investments through which measures are taken to reduce costs, which ultimately increases productivity and profitability of the enterprise.

Investments of the fifth group are directed to increase incomes, which in turn leads to an increase in profitability. This group of investments is mainly associated with the expansion of "traditional" activities of the enterprise.

The sixth group includes investments associated with significant risk (for example, designed to create new products or conquer new areas of activity or markets). Such investments are the most profitable in these areas (areas of activity of the enterprise), where there is no serious competition and therefore there is more freedom of action.

The division of investments into classes makes it possible to systematize the assessment of heterogeneous investment options. The classification of investments in terms of their profitability, which is carried out on the basis of different criteria and differentiation of the rate of return for different classes, is of the greatest practical importance for the investment policy of enterprises. This will allow managers to not only plan the profitability of various investment options, but also to systematically influence the investment policy of the enterprise.

Based on the analysis of economic practice from European and American enterprises, the approximate values required for the rate of return (the percentage of profit that must provide investment) for the above classes are summarized [268]:

- class one (obligatory investments) - there are no requirements but profit rates;

- class two (preservation of market positions) - profit rate 6\%; 
- class three (renewal of fixed assets) - profit margin 12\%;

- class four (cost savings) - profit rate 15\%;

- class five (increase in income) - the rate of return 20\%;

- class six ("risky" investments) - rate of return $25 \%$.

Requirements for the rate of return for certain types of investments for classes 2 - 6 (for example, investments in research and development) are not always set, which is due to their probabilistic nature.

At specific enterprises the priority of classes and the specified norms of profit can differ that reflects strategy and directions of development of the enterprise in the given concrete period. For example, class 2 investments (maintaining market positions) are more important for companies that need to maintain already won market positions. The same, albeit to a lesser extent, is true for investment in fixed assets. Cost savings are considered more definite than revenue increases. The first classes are generally considered more "reliable". However, the sequence of groups and the size of profit margins may vary depending on the development strategy of the enterprise. For example, in enterprises where significant expansion is planned, they may be the opposite. Investments to conquer new market segments are often included in Class 5, although in some cases may occupy other places in the classification, including immediately after forced investment.

The classification makes clear the investment policy of the enterprise and at the same time the strategic direction of its activities. In addition to the order of classes priority, compiled on the basis of the required rate of return, it is also important how much this rate of return differs in different classes. In recent years, investments in class 1 (in safety and environmental protection) have increased significantly. In modern conditions, when investments in environmental protection are beginning to play an increasingly important role, they can be divided into a separate class, which mainly takes place between 1 and 2 classes. In such cases, it is difficult to establish any exact rate of return for this class; it is set specifically in each case. The assessment of economic and socio-economic efficiency of investments in various above-mentioned areas of investment activities of enterprises should be based on special literature, taking into account the impact on production results and economic effect in the use of products. (1) Investment calculations and assessment of 
return on investment are reduced to two main types of calculations used in foreign economic practice. (2) They should be given special attention, as they provide an opportunity to identify the main prerequisites and approaches to assessing the return on investment. These main types of calculations are as follows:

1) Determining the profitability of this investment option;

2) Comparison and selection of best options in the case of several possible investments.

Determining the profitability of the investment option is carried out using the net present value method as follows. An investment option is profitable if the discounted value of income (income) at a certain estimated value of rent is not less than the present value of the relevant payments (expenses). This assumes that the estimated amount of value corresponds to the rate of return, which is important when planning an investment. Thus, the investment should not only provide a nominal amount sufficient to cover payments, but also provide for the receipt of investment not less than the above rate of return. The task of comparing the profitability of several investment options is somewhat more difficult than previous calculations. In investment theory, the criterion for choosing between several options is formulated as follows: the most profitable of several investment options is the one with the highest cost of capital, i.e the largest difference between the present value of income and payments. In these situations of alternative choice, it is usually implied that we are talking about two mutually exclusive options for investment. By logic, the criterion of profitability can be represented as follows: of the several investment options, the most profitable is the one for which the difference between annual revenues and payments, i.e net annual revenues, is maximum.

When calculating the return on investments, the payback period of investments is often chosen as an evaluation criterion. This method of payback also has several options, but common to them is that the assessment of profitability is based on a predetermined time period (payback period). This refers to the number of years during which the investment and the corresponding income from the receipt or reduction of payments reimburse (replace) the main investment. Capital investment is considered profitable if its payback period does not exceed the time planned by the management of the enterprise as 
a return on investment. The payback period should not be confused with the economic life of the investment. Usually the payback period is much shorter.

An important part of investment calculations is the analysis of their reliability, or, in other words, the assessment of the degree of risk in investment calculations, taking into account their probability. It is assumed that the calculations are based on alternative assumptions for several components simultaneously. This is due to the fact that if you need to more accurately determine the profitability of this investment project under different conditions the risk associated with it should be taken into account. To do this, one must first identify the appropriate components. The risk may be related to the prices of products and their components, the volume of products sold, wage costs and other factors.

To take into account these factors, one should build a so-called "decision tree". The sum of the probabilities of individual factors must be equal to one, which will mean taking into account the "decision tree" of all calculation cases.

If the risk is associated with many components that determine the return on investments, and if different options are possible, the "decision tree" becomes very complex. In this case, one should use additional mathematical tools for calculations, such as modelling. Once the probability of different options has been developed, a calculation of net annual income should be made for all cases. The results of the risk analysis can be clearly presented in the form of a risk profile, which graphically shows the probability of each possible case. Horizontally, the net annual income of the enterprise, vertically - the probability. Such graph shows the most probable net annual income.

Thus, investment planning is a complex process, one of the elements of long-term enterprise planning. It should be aimed at finding effective ways to develop the enterprise, the implementation of such investments that best meet the objectives of the enterprise, ensure the required level of profit and development of the enterprise. 